\title{
Local Temperature Control within a Confined Space by Using a Neural Network Model
}

\author{
Noriko TAKAHASHI ${ }^{1}$, Haruhiko MURASE ${ }^{2}$ and Katsusuke MURAKAMI ${ }^{2}$ \\ ${ }^{1}$ Graduate School of Agricultural and Life Sciences, The University of Tokyo, 1-1-1 \\ Yayoi Bunkyo-ku, Tokyo 113-8657, Japan \\ ${ }^{2}$ Graduate School of Agriculture and Biological Sciences, Osaka Prefecture University, 1-1, \\ Gakuen, Sakai, Osaka, 599-8531, Japan
}

\begin{abstract}
Precision agriculture is now practiced in plant factories. In the case of precision agriculture in Japan, the Microprecision Agriculture program is defined as an ultimate optimized plant production system utilized in order for plant factories to have environmental safeguards that are compatible with yield. Microprecision techniques to manage temperatures or other parameters in the plant factory can provide objectively controlled environments for specific purposes. In fact, in a plant factory, some environmental non-uniformity always exists within the interior. Most of the environmental factors in a fully controlled plant factory are observable and controllable. The conventional strategy for the environmental control of the interior of plant factories has been to make atmospheric factors, such as temperature and humidity, as uniform as possible throughout the interior space. This paper discusses an experiment to control local temperatures, as an example of how microprecision technology can be implemented in plant factories. The results of the experiment using a neural network model show that it is possible to control the temperature distributions by manipulating the wind directions and the temperatures of the airflow. This technique can also be implemented in people's living and working environments.
\end{abstract}

Keywords : microprecision agriculture, plant factory, distributed control, optimal management, Neural network model

\section{Introduction}

Ten years ago, as wasting energy and disrupting the environment were becoming increasingly serious problems, people in the USA became interested in environmental safeguards for agriculture. This led to the current movement that aims for the innovation of food production technology. First, the LISA(Low-Input Sustainable Agriculture) program was started as a systematic research movement to reduce the use of off -farm inputs with the greatest potential to harm the environment or the health of farmers and consumers ${ }^{11}$.

Received 6 November 2001

Accepted 20 March 2002
This is one of the operational definitions of sustainable agriculture. However, this project has been making little progress because LISA always improves traditional agriculture at the expense of yields by reducing or abolishing input chemical materials.

On the other hand, the implementation of precision agriculture $(\mathrm{PA})$ has been embraced. The difference between PA and LISA is that PA requires technological innovation while leaving other things unchanged, whereas LISA always involves revising or improving traditional practices. The open field agricultural system is a typical example of a large-scale complex system that has attracted the attention of researchers and scientists in various scientific and engineering fields. Now, with significant support from both the 
agricultural and industrial sectors, PA has become a promising practice that can successfully handle such a complex system. Precision agriculture can be implemented in an alternative cultivation system, such as a plant factory, to realize profitable agriculture. The research, development and dissemination of PA as an innovative agricultural technology of environmental safeguards based on utilizing information, sensor and software technologies ${ }^{2)}$ is being conducted throughout the world.

In fact, PA is an optimal management strategy, taking into account the existence of uneven soil fertility and moisture distribution in large -scale open fields in the US. This concept must be applied to environmental, energy and food safety issues that are currently difficult problems in Japan.

It is necessary to construct a Japanese form of PA because the field conditions in Japan are different from those in the USA. Although the plant factory is also a large-scale complex system, it is much less complex than the open field system. The fully controlled environment of a plant factory can be considered as an ideal cultivation system in terms of alternative agriculture. Most of the environmental factors in a fully controlled plant factory are observable and controllable ; therefore a plant factory can be optimized more easily than an open field. Precision agriculture can be implemented in alternative cultivation systems, namely, plant factories, to realize profitable agriculture. The term Microprecision Agriculture is therefore defined as a form of precision agriculture practiced in order for plant factories to have environmental safeguards that are compatible with yield.

The conventional strategy for the environmental control of the interior of plant factories has been to make the atmospheric factors, such as temperature and humidity, as uniform as possible throughout the entire interior space. In reality, some environmental non-uniformity always exists within the interior. In fact, some greenhouse techniques often take advantage of such non-uniform distribution to adjust harvesting times. However, in such cases, the environmental non-uniformity is still left uncontrolled.

Microprecision techniques for plant factory environ- mental control should be able to provide objectively controlled environments, including distribution. In this paper, local temperature controls as a microprecision technology for plant factories will be discussed.

\section{Local Environmental Control}

The goal of this study is to develop a technology for creating a desirable temperature distribution within a confined space exampled as Fig. 1. The specific objective was to model the relationship between the temperature distribution and the air mass properties by using a neural network model.

Most of the sample is an air curtain that is fitted at the entrance of a plant factory as shown in Fig. 2.

By blowing air and thus making a wind wall, it prevents cooling air from escaping. By applying this system, blowing air can divide a predetermined area into several temperature distributions.

By inputting wind direction, airflow rate and temperature, we can get the outputs of optimum temperature distribution as shown in Fig. 3. By providing the optimum temperature for a particular group of crops that are at the same growth stage, a better outcome in

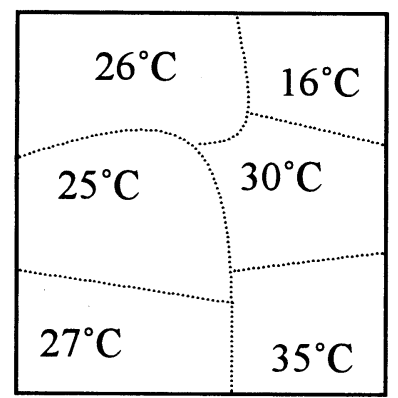

Fig. 1 An example of desirable temperature distribution

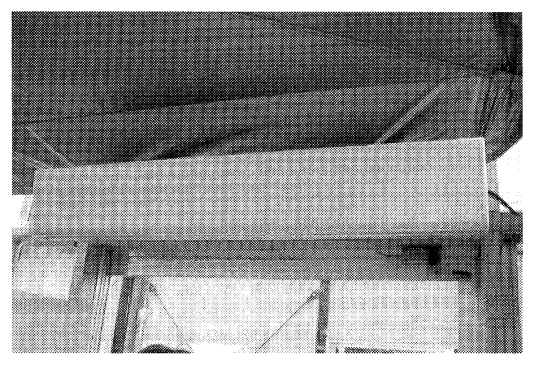

Fig. 2 Air curtain 


\section{Wind}

temperature

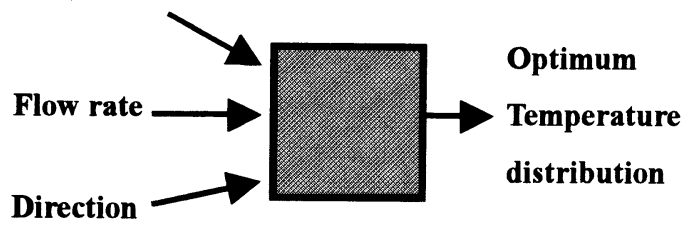

Fig. 3 Concept of local environmental control

terms of quality and yield can be expected.

The temperature distribution in a confined space can be controlled by varying the temperatures and directions of air masses blown into the space. The temperature distribution can be assumed to be a function of the temperatures and directions of the airflow properties.

In order to verify and control the local distribution of temperature, a prototype experiment was performed.

\section{Neural Network Model}

\section{Neural network model for estimation}

The temperature distribution can be assumed to be a function of the temperatures, directions, and flow rates of the air blown by the two fans. Thus, these relationships were modeled using a three layered neural network as shown in Fig. 4.

The training method was the backpropagation by generalized delta rule with the inertial modification. The sigmoid function was used for the transfer function of the processing neural network. The training was terminated when the margin of error converged to less than 1\%. The inputs were the desired temperature distributions. The number of the hidden layer units was determined based on the minimization of out put error by trial and error basis. The hidden layer was set 9 units. By inputting the desired temperature distributions, we obtained the directions and temperatures of the airflow.

\section{Development of the equipment}

Fig. 5 illustrates the experimental apparatus. The size is 1 cubic meter. Styrene foam was used for insulating material. Its thickness was $5 \mathrm{~cm}$. The box interior is divided into two spaces, and is fitted with two sirocco fans $(90 \mathrm{~mm} \times 70 \mathrm{~mm} \times 400 \mathrm{~mm}, 50 \mathrm{~W}$,
Input

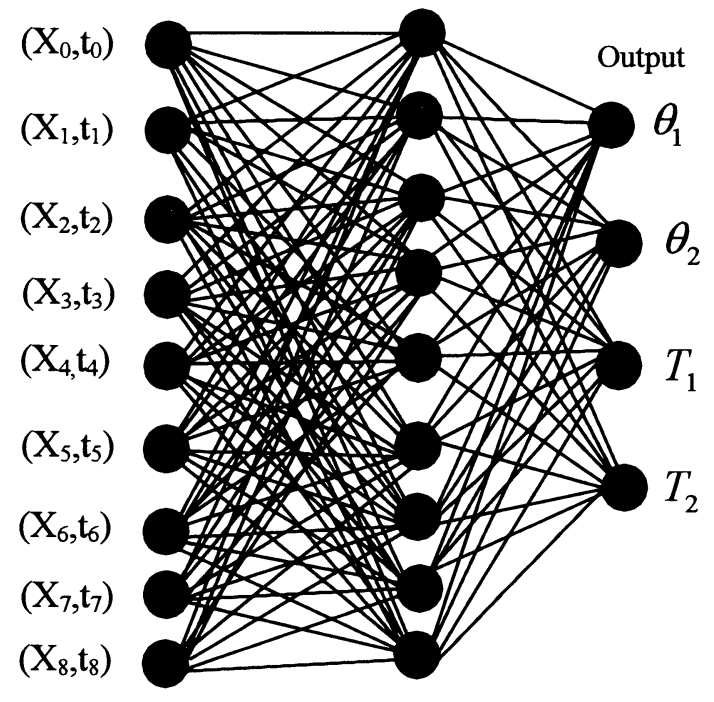

$\theta_{1}, \theta_{2}:$ Wind direction,

$T_{1}, T_{2}$ : Temperature of wind,

$\mathrm{Xn}$ : Location, $\mathrm{t}_{\mathrm{n}}$ : Temperature at the location $(\mathrm{n}=0,1, \ldots .8)$

Fig. 4 Neural network model

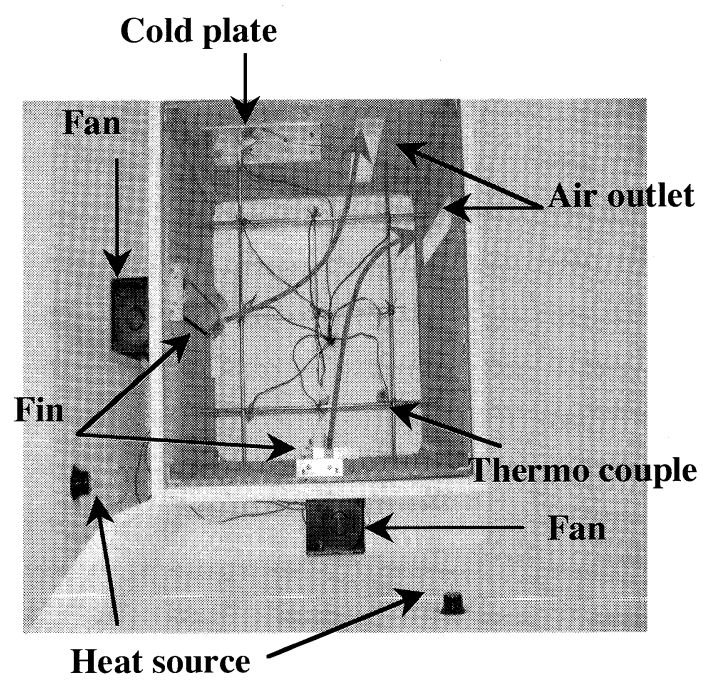

Fig. 5 Experimental Apparatus

Oriental motor, MF930BC). These fans create two major air streams. The winds go out through two exits. Each sirocco fan blows air in a predetermined direction controlled by fins. The air temperature 
blown from each fan can be adjusted independently at a specific temperature that can be different from the

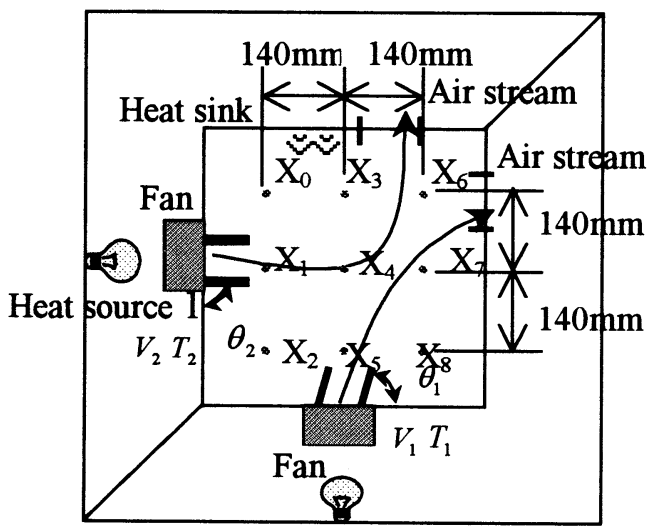

Heat source 2

\section{$\theta_{1}, \theta_{2}:$ Wind direction, $V_{1}, V_{2}:$ Air flow rate}

\section{$T_{1}, T_{2}:$ Temperature of wind}

Fig. 6 Locations of nine thermocouples for temperature distribution measurement

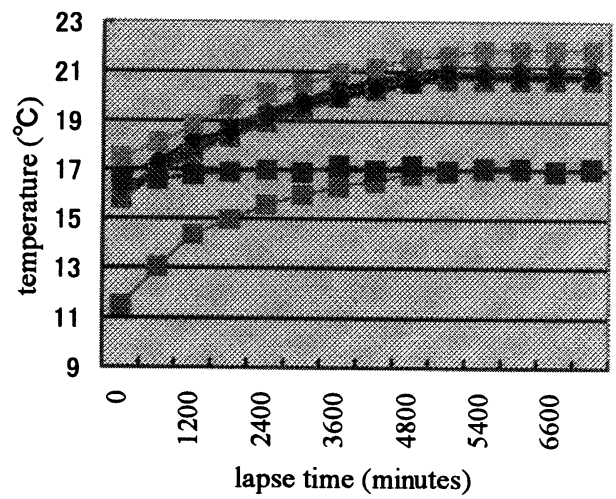

\begin{tabular}{|c|c|}
\hline $\begin{array}{c}(\mathrm{X} 0, \mathrm{t} 0) \\
(\mathrm{X} 2, \mathrm{t} 2) \\
-(\mathrm{X} 4, \mathrm{t} 4) \\
(\mathrm{X} 6, \mathrm{t} 6) \\
(\mathrm{X} 8, \mathrm{t} 8) \\
\mathrm{T} 2 \\
- \\
-\end{array}$ & 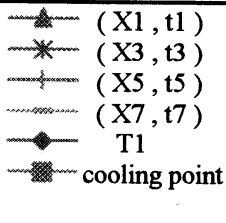 \\
\hline
\end{tabular}

Fig. 7 Example of measured temperature distributions (Direction $\theta_{1}=90.00^{\circ}, \theta_{2}=90.00^{\circ}$ ) temperature of the air blown by the other fan. The airflow rate from each fan can also be varied independently. Various temperature distributions in the chamber can occur, depending on the flow rates, temperatures and directions of the air blown by the two fans.

The temperature distribution can be measured at nine locations in the chamber by thermocouples (Copper-constantan) as shown in Fig. 6 . The 9 measuring points were set $8 \mathrm{~cm}$ above the bottom of interior box.

In this experiment, the airflow rates were fixed at 1. $3 \mathrm{~m} / \mathrm{s}$ and $1.15 \mathrm{~m} / \mathrm{s}$ and two light bulbs ( $40 \mathrm{~W}$ and $25 \mathrm{~W}$ ) were used as heat sources. Air temperature changed according to the amount of available heat (from the light bulbs) ; and the distribution of air temperature was calculated using the direction and temperature of the airflows.

\section{Training data}

Temperature distribution was measured at steady state at nine locations as shown in Fig. 7. Table 1 indicates an example of the measured temperature results at the nine locations. The neural network was trained by using these training data. Two measured temperature data were taken up as inspection data.

\section{Results and Discussions}

The training was converged at approximately 280000 times iteration.

Two measured temperature data that were taken up in advance were used for inspecting this neural network. The airflow temperatures and the air directions were estimated by inputting the check data as shown in Table 2. The average errors for the airflow directions and air temperatures were 3.53 and 0.45 respectively. For the airflow directions, the average error was less than $10 \%$. For the air temperature, the error was also acceptable for the low target temperature. For the high target temperature, the average error became less than $40 \%$.

By using these link weights from a neural network,

Table 1 Example of the measured temperatures at the nine locations $\left(\theta_{1}=90.00^{\circ}, \theta_{2}=90.00^{\circ}, T_{1}=20.93^{\circ} \mathrm{C}, T_{2}=21.68^{\circ} \mathrm{C}\right)$

\begin{tabular}{cccccccccc}
\hline \hline Location & $\mathrm{X}_{0}$ & $\mathrm{X}_{1}$ & $\mathrm{X}_{2}$ & $\mathrm{X}_{3}$ & $\mathrm{X}_{4}$ & $\mathrm{X}_{5}$ & $\mathrm{X}_{6}$ & $\mathrm{X}_{7}$ & $\mathrm{X}_{8}$ \\
\hline Temperature $\left({ }^{\circ} \mathrm{C}\right)$ & 20.69 & 21.18 & 21.02 & 20.84 & 20.97 & 20.74 & 20.88 & 20.91 & 20.88 \\
\hline
\end{tabular}


Table 2 Inspection data and estimated air temperatures and air directions by using a neural network model

\begin{tabular}{lrrrr}
\hline \hline & $\begin{array}{c}\text { Direction } \\
\theta_{1}\left({ }^{\circ}\right)\end{array}$ & $\begin{array}{c}\text { Direction } \\
\theta_{2}\left({ }^{\circ}\right)\end{array}$ & $\begin{array}{c}\text { Temperature } \\
T_{1}\left({ }^{\circ} \mathrm{C}\right)\end{array}$ & $\begin{array}{c}\text { Temperature } \\
T_{2}\left({ }^{\circ} \mathrm{C}\right)\end{array}$ \\
\hline Inspection data 1 & 135.00 & 45.00 & 22.83 & 25.95 \\
Estimated data 1 & 141.64 & 47.84 & 23.49 & 26.24 \\
Absolute error 1 & 6.64 & 2.84 & 0.66 & 0.29 \\
\hline Inspection data 2 & 135.00 & 90.00 & 31.49 & 32.71 \\
Estimated data 2 & 133.75 & 86.63 & 31.37 & 33.43 \\
Absolute error 2 & 1.25 & 3.37 & 0.12 & 0.72 \\
\hline
\end{tabular}

we can estimate the airflow temperatures and the air directions that are necessary for making desirable temperature distribution in a confined space.

\section{Conclusions}

The results of the experiment using a neural network model show that it is possible to control the temperature distributions by manipulating the wind directions and the temperatures of the airflow. Local environmental control technology is essential for providing optimal distributions of temperature or other environmental parameters in plant factory environments through the realization of microprecision agriculture. For example, in a traditional plant factory, crops at different growth stages are grown under the same temperature conditions in the same growing space. By utilizing this neural network model, which can determine proper temperatures and directions of air mass blown into the space to make desirable temperature distributions, we can locate crops at the optimum growing spaces corresponding to their various growth stages. By providing optimum temperature for a group of crops at the same growth stage, even in the same growth space, better outcomes in terms of quality, yield, harvesting labor and shipment can be expected. This local environmental control technology is applicable, not only to plant production systems, but also to human living environments. For example, it can be utilized to make an amenity space in which humans and plants live together in a confined space. Recently there has been increasing demand for introducing living plants into office workspaces, ordinary living rooms, indoor gardens, indoor sports facilities, and atriums, etc. It is obvious that optimum (or comfortable) temperature and humidity levels for plants and humans are different from each other. Therefore, this local environmental control technology could satisfy the needs of both plants and humans for comfortable living conditions.

\section{References}

1) National Research Council: Sustainable Agriculture Research and Education in the Field, National Academy Press, Washington, D. C. pp. 437 (1991)

2) National Research Council : Precision Agriculture in the 21st Century, National Academy Press, Washington, D. C. pp. 149 (1997)

3) Dan W. Patterson: Artificial Neural Networks, Prentice Hall, pp. 141-179 (1995)

4) Calculation \& Algorithm research: Neuro Computing using C language, Rassel Books, written in Japanese, pp. 14-79, 133-148 (1992)

5) Ichikawa, H.: Hierarchy neural network, Kyoritsu Shuppan, written in Japanese, pp. 1-33 (1993)

6) Neuronet group and Kiritani, S.: Neuro Computer, Gijyutsu-Hyoron, written in Japanese, pp. 15, 28-40 (1989)

7) Nagao, T.: Optimized Algorithm, Shoukodo, written in Japanese, pp. 104-115(2000)

\footnotetext{
ニューラルネットワークを用いた閉鎖空間内における局所温度環境制御

高橋憲子 ${ }^{1}$ ・村瀬治比古 ${ }^{2} \cdot$ 村上克介 $^{2}$

1東京大学大学院農学生命科学研究科 T113-8657 東京都文京区弥生 1-1-1

${ }^{2}$ 大阪府立大学大学院農学生命科学研究科 干599-8531 大阪府堺市学園町 1-1
} 